\title{
Research Paper: Dry Needling Plus Conventional Physiotherapy for Patients With Chronic Nonspe- cific Neck Pain: A Randomized Clinical Trial
}

\author{
Ghazaleh Vahedi $^{1}$ (D, Amir Letafatkar ${ }^{1}$ (D), Zahra Mosallanezhad ${ }^{2 *}$ (D, Malihe Hadadnezhad ${ }^{1}$ (D), Majid Menhaj ${ }^{3}$ (D), Seyed Sadredin Shojaedin ${ }^{1}$ (i)
}

1. Department of Biomechanics and Sport Injuries, Faculty of Physical Education and Sport Science, University of Kharazmi, Tehran, Iran. 2. Department of Physical Therapy, Research Center on Aging, University of Social Welfare and Rehabilitation Sciences, Tehran, Iran. 4. Department of Physical Therapy, University of Social Welfare and Rehabilitation Sciences, Tehran, Iran.

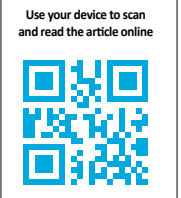

Citrat on Vahedi Gh, Letafatkar A, Mosallanezhad Z, Hadadnezhad M, Menhaj M, Shojaedin SS. Dry Needling Plus Conventional Physiotherapy for Patients With Chronic Nonspecific Neck Pain: A Randomized Clinical Trial. Physical Treatments. 2021; 11(3):157-170. http://dx.doi.org/10.32598/ptj.11.3.42.20

doi) $h$ http://dx.doi.org/10.32598/ptj.11.3.42.20

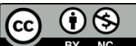

Article info:

Received: 06 Oct 2020

Accepted: 26 Dec 2020

Available Online: 01 Jul 2021

Keywords:

Neck pain, Physiotherapy, Dry needling, Disability, Ultrasonography

\begin{abstract}
A B S T RA C T
Purpose: This study aimed to evaluate the effect of conventional physiotherapy plus Dry Needling (DN) technique in patients with chronic nonspecific neck pain with Sternocleidomastoid (SCM) and Upper Trapezius (UT) muscles involvement.
\end{abstract}

Methods: This study was designed as a single-blind randomized clinical trial. A total of 39 patients (19 men and 21 women) with chronic non-specific neck pain with a Mean $\pm \mathrm{SD}$ age of $38.13 \pm 5.68$ years, a Mean \pm SD height of $168.28 \pm 8.34 \mathrm{~cm}$, and a Mean $\pm S D$ weight of $75.78 \pm 9.02$ $\mathrm{kg}$ participated in this study. They were randomly divided into conventional physiotherapy (control group: $\mathrm{n}=19$ ) and conventional physiotherapy plus $\mathrm{DN}$ (intervention group: $\mathrm{n}=20$ ). SCM and UT muscle pain, neck disability, and thickness were assessed for all participants in the pretest, post-test, and follow-up periods. This study was reviewed and approved by the Faculty of Physical Education and Sport Science, University of Kharazmi, Tehran, Iran. Repeated measures analysis of variance and Bonferroni post hoc tests were used for data analysis using SPSS v. 22.

Results: The results of 1-way analysis of variance showed that pain, neck disability, and SCM and UT muscle thickness in the intervention group had a significant decrease compared to the control group in the post-test and follow-up period $(\mathrm{P}<0.05)$. Also, according to the results of the corrected Bonferroni post hoc test, the intervention group showed a greater effect size than the control group in the post-test and the follow-up periods in the above variables.

Conclusion: The present study results show that adding DN to conventional physiotherapy for neck pain can increase the effectiveness of intervention in relieving pain, disability, and SCM and UT muscle thickness in people with chronic neck pain.

\section{* Corresponding Author:}

Zahra Mosallanezhad, PT, PhD.

Address: Department of Physical Therapy, Research Center on Aging, University of Social Welfare and Rehabilitation Sciences, Tehran, Iran. Phone: +98 (21) 22180039

E-mail:zmosallanezhad@yahoo.com 


\section{Highlights}

- The study is a quasi-experimental and double-blind randomized clinical trial on chronic non-specific neck pain.

- Adding dry needle to a conventional physiotherapy program would further reduce the severity of neck pain, further improve neck disability index,

-Adding dry needle to a conventional physiotherapy program would further improve neck disability index.

- Adding dry needle to a conventional physiotherapy program would further reduce thickness of Sternocleidomastoid (SCM) and Upper Trapezius (UT) muscles.

\section{Plain Language Summary}

Physiotherapists have access to many options of conventional Physiotherapy for patients. Nowadays, it is common that Physiotherapists use dry needling to release or inactivate trigger points to relieve pain or improve range of motion. Research supports that dry needling reduces pain and muscle tension, improve function, and facilitates return to active life. Previous studies suggested need for providing more evidence to support the value of adding dry needle conventional Physiotherapy. We conducted a randomized clinical trial to evaluate the effect of adding Dry Needle (DN) technique for Sternocleidomastoid (SCM) and Upper Trapezius (UT) muscles to conventional physiotherapy for patients with chronic nonspecific neck pain. Our results showed that adding dry needle to conventional Physiotherapy program would further reduce the severity of neck pain, further improve neck disability index, and further reduce muscle thickness in people with chronic nonspecific neck pain. This study provides a powerful evidence to support adding dry needle conventional Physiotherapy to improve the effectiveness of treatment for patients with chronic nonspecific neck pain.

\section{Introduction}

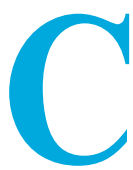

hronic neck pain is significantly common in the community-approximately twothirds of people experience neck pain at some point in their lives [1,2]. Neck disorders, in addition to pain and discomfort in the neck area, may refer pain to other areas, especially the head and upper limbs, and disturbs the patient's activity of daily living [3,4]. Muscles in the neck area and myofascial pain have a significant effect on the occurrence of pain and disorders in this area [5]. Myofascial pain may occur in muscles or fascia due to Trigger Points (TrPs). These points are small, painful, and sensitive points inside the muscle or fascia that can be active or latent. Active trigger points cause clinical symptoms such as referral pain, decreased use of the muscle group of that area, decreased muscle tone and strength, spasm and muscle hypertrophy, and decreased movement of the affected joints, but latent trigger points cause pain only when direct pressure by finger is applied $[2,5,6]$.

It is hypothesized that the presence of TrPs can increase acetylcholine abnormally, leading to increased muscle tension and the formation of the taut bands and hypoxia [5]. The cause of these TrPs is multifactorial, including improper posture, incorrect biomechanics, overuse, repetitive activities, direct trauma, or stress [7].

An intervention that targets neck muscle TrPs as part of a multi-stage treatment can help reduce symptoms in patients with neck pain [8]. TrPs in muscle can cause motor changes (such as reduced range of motion, weak areas, and decreased simultaneous contraction, as well as sensory changes such as pain and tenderness) [9]. TrPs may occur in any muscle, but they are more common in muscles involved in postural control, including the Sternocleidomastoid (SCM) and Upper Trapezius (UT) [10]. Numerous pharmacological and non-pharmacological treatments have been applied to treat myofascial pain syndrome in patients with neck pain. As a non-pharmacological method, physiotherapy, including electrical, physical, and manual techniques (myofascial release, muscle energy, mobilization, and manipulation), stretching, and exercise programs are also recommended. Although these approaches are effective, recently, the use of Dry Needling (DN) has been taken into attention by patients and medical staff $[5,11-$ 13]. The DN methods with or without injection are recommended to manage myofascial pain syndrome [14, 15]. Recently, the DN method and its clinical efficacy have received more attention and research [16]. 
The most common DN method is the myofascial, deep method in which the needle enters the trigger points directly [17]. The therapist finds the trigger point by touch and inserts the needle into the desired area. In this method, the local twitch response is followed by muscle relaxation. Compared to other physiotherapy modalities, DN is feasible to use and has been proposed as a method with rapid and effective treatment effects on TrPs. However, it is recommended to consider broadening the definition of DN to cover the stimulation of neural, muscular, and connective tissues, not just $\operatorname{TrPs}[13,18,19]$.

DN may release the tight muscle bands associated with trigger points and decrease pain, and improve function [19]. Of course, the optimal frequency, duration, and intensity of DN should be determined for many neuromusculoskeletal conditions. Many studies suggested manually stimulation of the needles and leaving them in situ for 10 to 30 minutes. Position statements and clinical practice guidelines for DN should be based on the best available literature [13]. But DN is an invasive method, and some patients have reported side effects. Also, it may add to the cost of treatment. From a clinical and practical point of view, the use of safer and easier therapies and at the same time achieving better therapeutic outcomes is emphasized [20].

Based on a systematic review and meta-analysis by Gattie et al., very low-quality to moderate-quality evidence suggests that DN performed by physical therapists is more effective than no treatment, sham DN, and other treatments for reducing pain and improving pressure pain threshold in patients presenting with musculoskeletal pain in the immediate to 12-week follow-up period. Low-quality evidence suggests superior outcomes with DN for functional outcomes than no treatment or sham needling [21].

Conducting precise and controlled RCT research on whether the addition of the DN technique to conventional physiotherapy can increase the effectiveness of treatment can provide valuable evidence for the clinical applications of DN therapy. This study aimed to investigate the effect of adding the DN technique to conventional physiotherapy using on upper trapezius and sternocleidomastoid muscles for patients with chronic nonspecific neck pain. Pain severity, neck pain disability index, and muscle thickness of sternocleidomastoid and upper trapezius were considered outcome measures.

\section{Materials and Methods}

\section{Preliminary and methodological study}

Initially, the reliability of muscle thickness measurement methods was evaluated in a methodological study. This research included 20 participants whose SCM and UT muscle thickness were measured at specific intervals (twice a day, one hour apart, and the third time, five days later) by the colleagues responsible for the assessments. The related details of the measuring method have been discussed in the method section.

\section{The main study}

This study was a single-blind randomized clinical trial. The study participants were selected from patients with non-specific chronic neck pain referred to a private physiotherapy clinic in Tehran, Iran, in 2019. Of volunteers, 39 participants were included according to the inclusion and exclusion criteria. The inclusion criteria were between 25 and 50 years old, had neck pain for at least three months, had active TrPs (at least two sensitive points in UT and SCM muscles) (Figure 1), and lacked a history of neck and shoulder myopathy, neuropathy, myelopathy and torticollis or neck, torso and shoulder surgery. The exclusion criteria included the subjects' unwillingness to continue participating in the study, using drugs that affect the central nervous system, such as sedatives, and defects in the visual field or abnormalities in the vestibular system. If we found subjects with possible contraindications of DN such as bruising, pneumothorax, infection, internal tissue damage, and bleeding, we would exclude them, too [2-5]

Firstly, the objectives and method of the study were explained for the subjects. All subjects signed the informed consent form in accordance with the Helsinki Declaration and voluntarily participated in the study. These participants were then divided into two groups through computer randomization. One group received conventional Physiotherapy (PT) as a control group and the second group received conventional Physiotherapy plus Dry Needling $(\mathrm{PT}+\mathrm{DN})$ as the intervention group. In both groups, conventional physiotherapy treatments included ultrasound (1 Meg, $1 \mathrm{~W} / \mathrm{cm} 2,5 \mathrm{~min}$ ), TENS (typical, 100 $\mathrm{Hz}, 20$ minutes), infrared ( 7 minutes), and exercise therapy for neck pain (isometric, range of motion, strengthening and stretching exercises) $[22,23]$ performed for 10 days (10 sessions, five days a week) [24].

In the intervention group, in addition to the conventional physiotherapy for neck pain, patients also received 

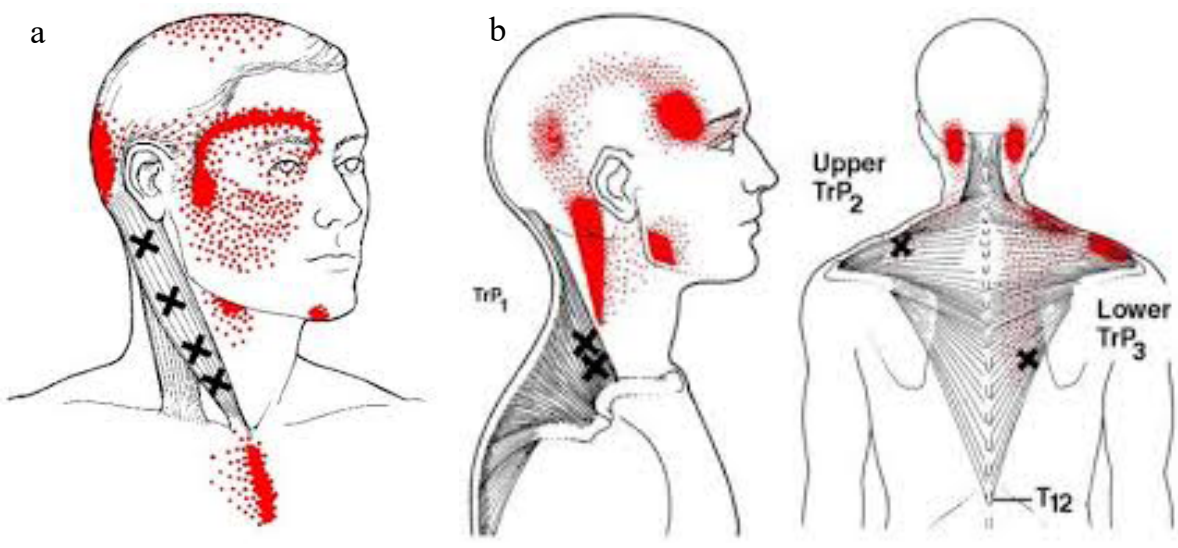

Figure 1. Triger points of sternocleidomastoid (a) and upper trapezius (b) [23]

PHYSICAL TREA $\|$ MENTS

DN for SCM and UT muscles in treatment sessions of 2, 5, and 8. DN was applied on active TrPs, for three sessions with an interval of 48 hours between sessions. In treatment sessions, the criterion for the needling to hit the trigger point was one of the following: creating a local twitch response or creating a sense of diffusion. Detecting active trigger points in SCM and UT was performed by the pincer palpation method [25]. The landmark to find the TrPs was that when we squeezed them, pain and inconvenience were felt by the patient. Then, DN was applied on three active trigger points found on the main bulk of each target muscle [26].

\section{DN of sternocleidomastoid muscles}

The patient lies down in a supine position. Once the carotid artery is identified, both muscle heads, clavicular and sternal, are pulled up for pinching. The needle is then inserted perpendicular to the skin and the therapist's fingers. The needle can be inserted from front to back or from back to front. A sterile acupuncture needle with a diameter of $0.25 \mathrm{~mm}$ and a length of $2 \mathrm{~cm}$ is used. Before starting the treatment with DN, the therapist first washes his hands and uses sterile latex gloves, and also cleanses the skin on the desired area with alcohol. The needle is then inserted into the skin on the affected trigger point to slowly reach the trigger point and then moved up and down five times. Induction of pain or local twitch response indicates the correct location of the needle. The carotid artery is inside the sternocleidomastoid muscle near the trachea. We pinched the muscle away from the artery and inserted the needle vertically between the fingers that pinned the muscle, and avoided the needle entering the artery $[27,28]$.

\section{DN of the upper trapezius muscle}

The patient lies down in a supine position, with the head is on the pillow in a normal position and the hands are next to the body. A sterile acupuncture needle with a diameter of $0.25 \mathrm{~mm}$ and a length of $2 \mathrm{~cm}$ is used. Before starting the dry needle treatment, the cleansing method is used for the desired area. The therapist first washes his hands and uses sterile latex gloves, and also cleanses the skin on the affected area with alcohol. The needle is then inserted into the skin on the affected trigger point to slowly reach the trigger point and then moved up and down five times. The direction of the needle should not be towards the lungs. When the muscle is gripped toward the head, the needle is inserted between the therapist's fingers and perpendicular to the ground. Induction of pain or local twitch response indicates the correct location of the needle.

In this method, a needle is used on the muscle at the main point, i.e., between the thorny appendage of the seventh vertebra and the acromion. Regardless of the local response, the needle is held at any point for $3 \mathrm{~min}$ utes. This process is repeated three times, and each time the patient rests for 5 minutes. The DN was applied for three sessions with an interval of 48 hours between sessions. It should be noted that in treatment sessions, the criterion for the needle to hit the trigger point is one of the following: creating a local twitch response or creating a sense of diffusion [29, 30].

Outcome measures included pain, neck pain disability index, and muscle thickness of SCM and UT in patients with chronic nonspecific neck pain. Using valid and reliable tools [25-35], the evaluation was performed at the first session (before the intervention), after the last treatment session, and one month after the treatment (follow-up). To observe the blindness of the study and to 


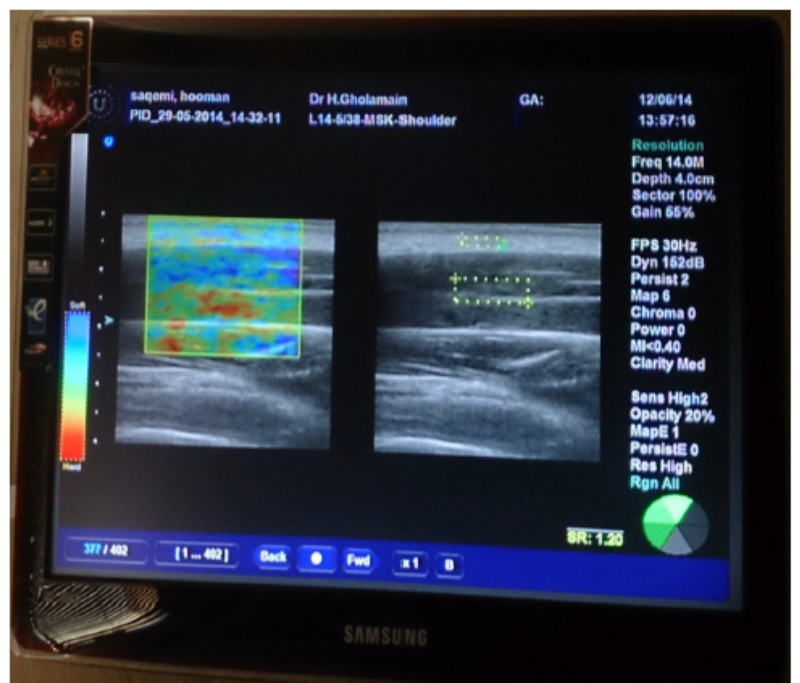

Figure 2. Sonography device [23]

prevent bias, two things were considered. First, the patients were randomly placed in the control or treatment groups by a computer randomization method. Second, an experienced physiotherapist performed the treatment, and another physiotherapist performed the evaluation as the research colleague who was unaware of the grouping

\section{Study instruments}

\section{Research consent form}

It was a form provides potential research participants sufficient written information to decide whether to participate in the research study or not, based on an explanation of the proposed research and the nature of the participation that was requested of them.

\section{General information questionnaire}

The general questionnaire was used to collect background information such as age, weight, height, and history of disease and medications used, history of acute and severe trauma to the neck, and other information of individuals. The examiner completed this questionnaire through a face-to-face interview. The obtained data by this questionnaire controlled the health, or illness, and injury conditions of the participants and the inclusion criteria.

\section{Scales and tape measures}

The weight and height of the participants were measured using scales and tape meters.

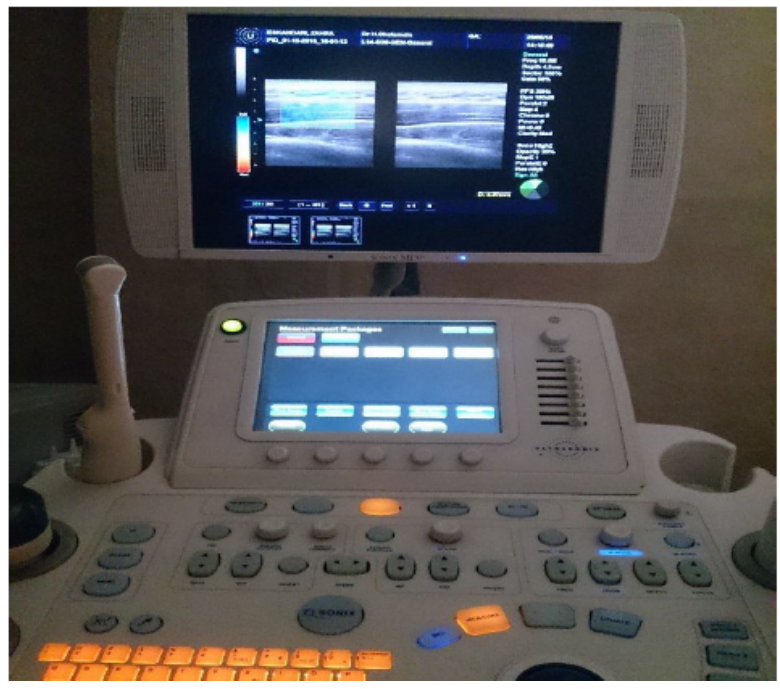

PHYSICAL TREA IMENTS

Visual Analog Scale (VAS) of Pain

Subjects' pain intensity was measured using the Visual Analog Scale (VAS), which is standardized and is a valid and reliable tool for measuring pain. This scale is divided from zero (painless) to ten (most severe pain). This scale is a $10-\mathrm{cm}$ line on which the pain is rated between 0 and 10. According to the guidelines of this scale, 0 indicates the absence of pain, the number 1 to 3 indicates mild pain, the number 4 to 6 indicates moderate pain, and the number 7 to 10 indicates severe pain. The subjects were asked to report two separate scores for their pain intensity, one related to the highest pain intensity they experienced and the other related to pain intensity when filling out the questionnaire [31].

\section{Neck Disability Index Scale (NDI)}

This scale is used to assess the degree of functional disability in patients with neck pain. In this study, the Persian version of the neck functional disability questionnaire was used. This questionnaire is completed, and its validity and reliability have been shown. It consists of 10 sections, and each of these 10 sections has a score from 0 to 5 . So, the maximum score was 50 . The percentage of disability score was calculated by multiplying the total points obtained by 100 and then dividing by a score of 50 . Total acquired score/Total protentional score=disability score. Its scales include the following:

$(0-4)=$ no disability, $(14-5)=$ mild, $(15-24)=$ moderate, $(25-34)=$ severe,$($ above 34$)=$ complete disability

It has been suggested that there should be a difference of at least 5 points to be clinically significant. If the pa- 
tient score difference remains between 5-15, it means that the recovery rate is excellent $[32,33]$.

\section{The physiotherapy devices}

These devices include ultrasound (model 215P), TENS (model 620P), both manufactured by Novin Medical Engineering Company, Iran, and Infrared (manufactured by Noavaran company).

\section{Needle}

Needles with a length of $2 \mathrm{~cm}$ and a diameter of 0.25 $\mathrm{mm}$ were used to perform the dry needle method [26-30].

\section{Ultrasound device}

Using a B-mode ultrasound device (Ultrasound, logia 100, General Electrics, Milwaukee, WI) and $7.5 \mathrm{MHz}$ linear probes (Figure 2), we recorded the maximum vertical distance between the lower and upper hyperechogenic margins of the muscle, as the maximum thickness of anatomical transverse muscle or cross-section. To measure muscle thickness using ultrasound at each stage before and after treatment and follow-up, we measured each image three times and recorded their mean as the actual size $[28,34,35]$. The reliability of the ultrasound measurement method was evaluated by assessing the outcomes in the present study.

\section{Evaluation of sternocleidomastoid muscle thick- ness}

First, the patient is placed on the bed in a supine position so that the hands are placed on the special line next to the body and head and neck in the midline and normal position without any lateral deviation. The patient is asked to breathe normally and not to speak. The head is then rotated slightly toward the opposite of the muscle measured. The sternal head of this muscle is located on the outer side of the cricoid cartilage. The probe is then placed on the muscle at the trigger points so that the transducer is located in the front of the neck, parallel to the direction of the trachea, and approximately $5 \mathrm{~cm}$ from the midline. Muscle fibers should be seen in parallel.

It should be noted that the center point of the probe is located on the area that is already marked on the muscle and is adjusted so that the direction of the muscle fibers is parallel to it and the two ends of the muscle are in the thickest position. Therefore, the longitudinal image of the SCM muscle is recorded, and the maximum muscle thickness is measured in the middle of the probe. Thus, the maximum distance between the lower and upper hyperechogenic margins of the muscle is recorded as the maximum thickness of the SCM muscle. All assessments are performed without applying pressure to the skin, and a thin layer of gel is applied between the transducer and the skin. All measurements are made at the end of the patient and examiner's exhalation. For ultrasound at each stage before and after treatment, each image is measured three times, and their mean is recorded as the actual size [23, 28, 34, 35].

Evaluation of the upper trapezius muscle thickness

All participants were evaluated using a supersonic ultrasound device equipped with two screens (ultrasound, Logia 100, General Electrics, Milwaukee, WI) and a 7.5 $\mathrm{MHz}$ linear probe at the trigger points of the UT muscle. First, the patient was placed on the bed in a position with the head in the neutral position, with the shoulder bent at 0 degrees, the elbow in the flat position completely, and the forearm in the neutral position, with no lateral deviation. The patient was then asked not to move his head or neck in any way or to speak during the assessment. The probe was then placed on the muscle at the point of trigger points so that the muscle fibers were seen in parallel. It should be noted that the center point of the probe was placed on a pre-defined area on the muscle and was adjusted so that the direction of the muscle fibers was parallel to it and the two ends of the muscle were in the thickest position. Therefore, the longitudinal image of the UT muscle was recorded, and the maximum muscle thickness was measured in the middle of the probe. Thus, the maximum distance between the lower and upper hyperechogenic margins of the muscle was recorded as the maximum muscle thickness and the distance between the lower and upper muscles as the maximum thickness of the upper trapezius muscle. All evaluations were performed without applying pressure to the skin, and a thin layer of gel was applied between the transducer and the skin to ensure this. All measurements were performed at the end of the patient and examiner exhalation. For sonography at each stage before and after treatment, each image was measured three times, and their mean was recorded as the actual size $[36,37]$.

\section{Ethical consideration}

The objectives and method of this study were reviewed and approved by the Research Ethics Committee of the Faculty of Physical Education and Sport Science, University of Kharazmi, Tehran, Iran. 
Table 1. Absolute and relative reliability indices of SCM and UT muscle thickness measurement methods in patients with non-specific chronic neck pain

\begin{tabular}{|c|c|c|c|c|c|}
\hline \multicolumn{2}{|c|}{ Variables } & SEM & ICC & Lower Limit & Upper Limit \\
\hline \multirow{3}{*}{ Right SCM } & Within day & 0.051 & 0.91 & 0.61 & 0.85 \\
\hline & & & & & \\
\hline & Between day & 0.069 & 0.89 & 0.59 & 0.84 \\
\hline \multirow{3}{*}{ Left SCM } & Within day & 0.058 & 0.88 & 0.58 & 0.92 \\
\hline & & & & & \\
\hline & Between day & 0.074 & 0.87 & 0.74 & 0.90 \\
\hline \multirow{3}{*}{ Right UT } & Within day & 0.045 & 0.89 & 0.64 & 0.86 \\
\hline & & & & & \\
\hline & Between day & 0.057 & 0.86 & 0.58 & 0.76 \\
\hline \multirow{2}{*}{ Left UT } & Within day & 0.071 & 0.92 & 0.66 & \\
\hline & Between dav & 0064 & 087 & 0.57 & \\
\hline
\end{tabular}

SCM: Sternocleidomastoid; UT: Upper Trapezius; ICC: Interclass Correlation Coefficients; SEM: Standard Error of Measure.

\section{Statistical method}

SPSS v. 22 was used for statistical analyses. Calculation of Interclass Correlation Coefficients (ICC) and Standard Error of Measure (SEM) indices were used to evaluate the level of relative and absolute reliability of measurement methods. The analysis of variance test of $2 \times 3$ mixed factor model to investigate the main and interaction effects of group and time factors on the dependent variables studied and Bonferroni post hoc tests were used to examine the mean differences between the two groups.

\section{Results}

The findings regarding the reliability tests of the measured muscle thickness (within and between days)

The reliability study included 20 participants. The findings are presented in Table 1. The ICC values with 95\% confidence limits, as well as the SEM values for each variable, are calculated and presented in Table 1.
The ICC values between 0.26 to 0.49 are low-reliability values, 0.50 to 0.69 as moderate reliability values, 0.70 to 0.89 as high-reliability values, and 0.90 to 1 as very high-reliability values [38].

According to Table 1, the reliability of the above variables, including the maximum thickness of the right and left sternocleidomastoid muscles and the maximum thickness of the right and left upper trapezius muscles, are high to very high.

\section{Descriptive findings of data}

Table 2 presents the Mean \pm SD of the demographic characteristics of the study participants.

\section{Findings regarding testing of research hypotheses}

Hypothesis 1: The effect of adding dry needling technique to conventional physiotherapy on pain in patients with chronic nonspecific neck pain. As shown in Tables 3 and 4, the results of 1-way analysis of variance and

Table 2. Mean $\pm S D$ of participants' demographic characteristics $n=20$

\begin{tabular}{|c|c|c|}
\hline \multirow{2}{*}{ Variables } & \multicolumn{2}{|c|}{ Mean $\pm S D$} \\
\hline & Conventional Physiotherapy Plus Dry Needle & Conventional Physiotherapy \\
\hline Age (y) & $169.35 \pm 10.31$ & $161.20 \pm 7.47$ \\
\hline Height $(\mathrm{cm})$ & $169.35 \pm 12.56$ & $167.20 \pm 9.78$ \\
\hline Weight (kg) & $77.10 \pm 12.56$ & $74.45 \pm 11.55$ \\
\hline Gender & 10 men-10 women & 9 men-11 women \\
\hline
\end{tabular}


Table 3. Mean $\pm S D$ of pain intensity and neck disability index of participants in pre-test, post-test, and follow-up assessments

\begin{tabular}{|c|c|c|c|c|}
\hline \multirow{2}{*}{ Variables } & \multirow{2}{*}{ Groups } & \multicolumn{3}{|c|}{ Mean $\pm S D$} \\
\hline & & Pre-test & Post-test & Follow-up \\
\hline \multirow{2}{*}{$\begin{array}{l}\text { Visual Analog Scale (VAS) } \\
\qquad(\mathrm{mm})\end{array}$} & $\begin{array}{c}\text { Conventional physiotherapy plus } \\
\text { dry needling }\end{array}$ & $7.96 \pm 1.37$ & $3.50 \pm 1.62$ & $3.20 \pm 1.83$ \\
\hline & Conventional physiotherapy & $7.71 \pm 1.24$ & $4.63 \pm 1.22$ & $4.56 \pm 1.41$ \\
\hline \multirow{2}{*}{ Disability index } & $\begin{array}{l}\text { Conventional physiotherapy plus } \\
\text { dry needling }\end{array}$ & $36.05 \pm 6.42$ & $15.95 \pm 6.26$ & $13.01 \pm 5.12$ \\
\hline & Conventional physiotherapy & $35.65 \pm 5.45$ & $21.65 \pm 5.42$ & $19.95 \pm 2.33$ \\
\hline
\end{tabular}

PHYSICAL TREA $\ M E N T S$

the corrected Bonferroni post hoc test indicate that by adding the DN technique to conventional physiotherapy, the pain intensity of patients with chronic nonspecific neck pain compared to the control group had a further decrease. According to the results, DN intervention, in addition to conventional physiotherapy, had a greater effect size than the control group both in the post-test period $(\mathrm{P}=0.012)$ and in the follow-up period regarding the pain variable $(\mathrm{P}=0.047)$.

Hypothesis 2: The effect of adding dry needling technique to conventional physiotherapy on the disability index of patients with chronic nonspecific neck pain. As shown in Tables 2 and 3, the results of 1-way analysis of variance and the corrected Bonferroni post hoc test indicate that by adding the DN technique to conventional physiotherapy, the disability index in patients with chronic nonspecific neck pain compared with the control group decreased further over time. According to the results, DN intervention and conventional physiotherapy had a greater effect size than the control group in the follow-up period regarding the disability index variable $(\mathrm{P}=0.032)$.

Hypothesis 3: The effect of adding dry needling technique to conventional physiotherapy on the upper trapezius and sternocleidomastoid muscle thickness in pa- tients with chronic nonspecific neck pain. As shown in Tables 5 and 6 , the results of 1-way analysis of variance and the corrected Bonferroni post hoc test indicate that by adding the DN technique to conventional physiotherapy, the thickness of the upper trapezius and sternocleidomastoid muscles in patients with chronic nonspecific neck pain showed more decrease in time, compared with the control group. Based on the results, DN intervention, in addition to conventional physiotherapy, had a greater effect size than the control group in post-test for the upper trapezius muscle $(\mathrm{P}=0.032)$ and follow-up for sternocleidomastoid muscle thickness $(\mathrm{P}=0.026)$ and for the upper trapezius muscle $(\mathrm{P}=0.024)$.

\section{Discussion}

The results of this randomized clinical trial study showed that adding dry needling to conventional physiotherapy would further reduce the severity of neck pain, improve neck disability index, and reduce SCM and UT muscle thickness in patients with chronic nonspecific neck pain. Overall, the results showed that pain, neck disability index, and change in SCM and UT muscle thickness in the conventional physiotherapy plus dry needling group had significant changes $(\mathrm{P}<0.05)$ in the post-test and follow-up periods compared to the control group.

Table 4. The effect size regarding pain intensity and disability index

\begin{tabular}{|c|c|c|c|c|c|c|c|}
\hline \multirow[b]{2}{*}{ Variables } & \multirow[b]{2}{*}{ Compared Groups } & \multicolumn{2}{|l|}{ Pre-test } & \multicolumn{2}{|l|}{ Post-test } & \multicolumn{2}{|l|}{ Follow-up } \\
\hline & & $\begin{array}{l}\text { Effect Size and 95\% Con- } \\
\text { fidence Interval (Lower } \\
\text { Limit-Upper Limit) }\end{array}$ & $\mathbf{P}$ & $\begin{array}{c}\text { Effect Size and 95\% } \\
\text { Confidence Interval (Lower } \\
\text { Limit-Upper Limit) }\end{array}$ & $\mathbf{P}$ & $\begin{array}{l}\text { Effect Size and 95\% Con- } \\
\text { fidence Interval (Lower } \\
\text { Limit-Upper Limit) }\end{array}$ & $\mathbf{P}$ \\
\hline $\begin{array}{l}\text { Visual } \\
\text { Analog Scale } \\
\text { (VAS) }\end{array}$ & $\begin{array}{l}\text { Conventional } \\
\text { physiotherapy } \\
\text { plus dry needle } \\
\text { with the control } \\
\text { group }\end{array}$ & $\begin{array}{c}0.19 \\
(-0.42-0.81)\end{array}$ & 0.880 & $\begin{array}{c}-0.78 \\
(-1.43-0.14)\end{array}$ & $0.012^{*}$ & $\begin{array}{c}-0.83 \\
(-1.47-0.18)\end{array}$ & $0.047^{*}$ \\
\hline $\begin{array}{l}\text { Disability } \\
\text { index neck } \\
\text { pain }\end{array}$ & $\begin{array}{l}\text { Conventional } \\
\text { physiotherapy } \\
\text { plus dry needle } \\
\text { with the control } \\
\text { group }\end{array}$ & $\begin{array}{c}0.55 \\
(-0.06-0.68)\end{array}$ & 0.199 & $\begin{array}{c}-0.97 \\
(-1.62-0.31)\end{array}$ & 0.269 & $\begin{array}{c}-1.47 \\
(-2.47-1.01)\end{array}$ & $0.032^{*}$ \\
\hline $\mathrm{P}<0.05$ & & & & & & PHYSICAL TREA & MENTS \\
\hline
\end{tabular}


Table 5. Mean \pm SD of SCM and UT muscle thickness

\begin{tabular}{|c|c|c|c|c|}
\hline \multirow{2}{*}{ Variables } & \multirow{2}{*}{ Groups } & \multicolumn{3}{|c|}{ Mean \pm SD } \\
\hline & & Pre-test & Post-test & Follow-up \\
\hline \multirow{2}{*}{\multicolumn{5}{|c|}{ Conventional physiotherapy plus dry needling }} \\
\hline & & & & \\
\hline & Conventional physiotherapy & $9.50 \pm 2.49$ & $8.90 \pm 3.41$ & $8.65 \pm 1.26$ \\
\hline \multirow{2}{*}{\multicolumn{5}{|c|}{ Conventional physiotherapy plus dry needling }} \\
\hline & & & & \\
\hline & Conventional physiotherapy & $13.85 \pm 3.01$ & $13.20 \pm 1.82$ & $13.00 \pm 1.63$ \\
\hline
\end{tabular}

The effects of adding Dry Needling (DN) to conventional physiotherapy on pain and functional disability

The pain gradually decreased over time in the intervention group compared to the control group. There are pros and cons to the effects of $\mathrm{DN}$ on pain in people with myofascial pain syndrome. Ilbuldu et al. showed that Trigger Point Dry Needling (TrPDN) has no significant short-term or long-term effects on reducing pain in people with upper trapezius muscle myofascial pain syndrome [39]. One of the important indicators of DN use in people with myofascial pain syndrome is the mechanical stimulation of TrPs. Baldry et al. showed that following the use of TrPDN, the pain was reduced in $87 \%$ of cases at the target site, which was permanent in $31 \%$ of cases [40]. In line with the present results, Rezaeian et al. found the positive effects of the DN technique on trigger points of the sternocleidomastoid muscle in migraine headache [28]. Using deep dry needling and passive stretch is more effective than passive stretch only in managing trapezius muscle myofascial pain syndrome in neck pain [40]. A study on individuals with TrPs in the UT muscle revealed that both DN and trigger point compression produced a 3-month improvement in pain intensity and disability [30].
The segmental and central mechanisms have been proposed as the mechanisms by which TrPDN reduces pain. Mechanical stimulation to sensitive muscle receptors due to needle placement reduces metabolic mediators and increases local microcirculation. A possible reduction in chemical mediators may be related to observing an immediate reduction in pain and tenderness after TrPDN. Applying mechanical needle stimulation to TrPs is likely to have positive effects on the associated myofascial system. These effects include improved fiber structure, reduced local stiffness, and improved blood circulation. It seems that the application of mechanical stimulation increases the production of smooth muscle actin and repair of fascia in the affected areas $[14,26]$. Liptan concluded that therapies that cause direct mechanical stimulation of connective tissue could eliminate connective tissue fibrosis. On the other hand, DN can establish homeostasis in fascia by destroying excess collagen connections and subsequently reduce tension in connective tissue [42].

Sterling et al. did not confirm the short-term effect of DN but has shown better effects in the long term [43]. Cagnie et al. also showed that DN could increase blood circulation in areas further from the DN area and even in the opposite muscle. It is showed that DN could increase blood circulation approximately twice in the central region of TrP, as studies have shown decreased blood cir-

Table 6. The effect size of the SCM and UT muscle thickness

\begin{tabular}{|c|c|c|c|c|c|c|c|}
\hline \multirow[b]{2}{*}{ Variables } & \multirow[b]{2}{*}{ Compared Groups } & \multicolumn{2}{|l|}{ Pre-test } & \multicolumn{2}{|l|}{ Post-test } & \multicolumn{2}{|l|}{ Follow-up } \\
\hline & & $\begin{array}{c}\text { Effect Size and 95\% } \\
\text { Confidence Interval } \\
\text { (Lower Limit-Upper } \\
\text { Limit) }\end{array}$ & $\mathbf{P}$ & $\begin{array}{l}\text { Effect Size and 95\% Con- } \\
\text { fidence Interval (Lower } \\
\text { Limit-Upper Limit) }\end{array}$ & $\mathbf{P}$ & $\begin{array}{l}\text { Effect Size and 95\% Con- } \\
\text { fidence Interval (Lower } \\
\text { Limit-Upper Limit) }\end{array}$ & $\mathbf{P}$ \\
\hline $\begin{array}{l}\text { Muscle } \\
\text { thickness } \\
\text { of SCM }\end{array}$ & $\begin{array}{l}\text { conventional physio- } \\
\text { therapy plus } \\
\text { dry needle } \\
\text { with the control group }\end{array}$ & $\begin{array}{c}0.07 \\
(-0.54-0.69)\end{array}$ & 0.987 & $\begin{array}{c}-0.07 \\
(-0.69-0.54)\end{array}$ & 0.110 & $\begin{array}{c}0.63 \\
(-1.26-0.00)\end{array}$ & $0.026^{*}$ \\
\hline $\begin{array}{l}\text { Muscle } \\
\text { thickness } \\
\text { of UT }\end{array}$ & $\begin{array}{l}\text { conventional physio- } \\
\text { therapy plus } \\
\text { dry needle } \\
\text { with the control group }\end{array}$ & $\begin{array}{c}0.03 \\
(-0.58-0.65)\end{array}$ & 0.867 & $\begin{array}{c}1.21 \\
(0.62-1.78)\end{array}$ & $0.032^{*}$ & $\begin{array}{c}1.63 \\
(0.94-2.30)\end{array}$ & $0.024^{*}$ \\
\hline
\end{tabular}


culation and increased lactate in this muscle only after 30 minutes of repetitive activity [44]. In the present study, the results showed that over time, functional disability in the intervention group decreased more. Also, in the present study, the effects of DN in follow-up on reducing functional disability were more, while in the DN group in follow-up, functional disability was reduced.

The effects of DN therapies on functional disability in people with myofascial pain syndrome have been different [29, 30, 44-48]. Research by Pecos-Martin et al. showed that TrPDN could increase functional ability in people with neck pain [46]. Pavkovich also showed that TrPDN application improves neck functional ability [47]. Similar results were reported in the study of Gerber et al. [29]. Ziaeifar et al. showed that following three sessions of TrPDN treatment of the upper trapezius muscle, the functional ability of the arm improved [30]. Pavkovich showed that TrPDN on the muscles of the upper trapezius, supraspinatus, infraspinatus, and levator scapula did not alter the range of motion of the neck and shoulders. However, the reason for this was the fusion of the cervical vertebrae [47]. Rock and Rainey showed that performing two DN sessions with electrical stimulation on the dorsal spine improves pain and range of motion in people with multifidus muscle myofascial pain syndrome [48]. It should be noted that these researchers did not report any explanation for the change in these parameters. Also, the changes were measured in the short term. In this study, there was no control group, and DN was not studied alone, but with electrical stimulation with a frequency of $1.5 \mathrm{~Hz}$, which may reduce pain [48].

The study results showed that adding TrPDN to physiotherapy exercises reduces the index of neck disability. Our results are consistent with the study by LeónHernández et al. They reported that neck disability was significantly reduced after the use of DN and the combination of DN and percutaneous electrical nerve stimulation [49]. In general, the results of the present study and other studies show that the TrPDN technique reduces pain and improves the ability of patients. In line with the results of our study, several studies have shown that reducing neck pain can improve its function.

In a systematic review and meta-analysis, Rahou-ElBachiri et al. showed no significant effects of TrPDN for managing knee pain syndromes at mid- or long-term follow-ups. They argue the risk of bias was generally low, but the heterogeneity and the imprecision of the results downgraded the level of evidence. They concluded low to moderate evidence suggests a positive effect of TrP$\mathrm{DN}$ on pain and related disability in patellofemoral pain, but not knee osteoarthritis or post-surgery knee pain, in the short-term. They emphasized the need for high-quality trials investigating the long-term effects of DN [50].

Neck muscles' TrPs, are not only the source of pain and discomfort in the neck area but also pain in other areas, especially the head and upper limbs. Consequently, these patients limit the use of the muscle group of that area. They face muscle weakness and spasm and decreased movement of the affected joints, and limited Range of Motion (ROM). Through releasing the TrPs and related tight muscle bands, DN can cause an immediate reduction in local, referred, and widespread pain, better motor control, muscle activation patterns, and finally, improved Activities of Daily Living (ADL) and function. DN also affects decreasing peripheral and central sensitization. DN also affects decreasing peripheral and central sensitization. In response to some stimuli, a high-pitched and sharp sensitivity may normally occur in the central or peripheral nervous system. Following an injury, a normal sensitization response is arising to help prevent additional harm. This condition may also present in many chronic pain conditions. In pathological conditions, sensitization may produce pain stimuli even if no harmful events are occurring [2-9, 19, 51-59].

The effects of adding Dry Needling (DN) to conventional physiotherapy on muscle thickness

In the present study, the muscle thickness in the TrPDN group showed a significant decrease between before and after follow-up. On the other hand, the highest slope of muscle thickness reduction was related to the TrPDN group, which was observed between before and after treatment. The reason for this effect seems to be the local muscle twitch response following DN application [26]. Ultrasound is an advanced instrument that measures muscle function non-invasively [34]. Ultrasound examination of muscle thickness has shown varied and sometimes contradictory results in different muscles [27-29, 59].

In patients with nonspecific neck pain, TrPDN with PT significantly reduced SCM and UT muscle thickness compared to the control group in follow-up. These results are consistent with the study by Martín-Rodríguez et al. [27]. Excessive SCM muscle thickness in patients with neck pain can be attributed to misuse of the deep neck flexor muscles, the dominance of superficial neck flexors (such as the SCM muscle) in neck flexion movements, tonic contraction of the SCM muscle, and persistent flexion $[35,60]$. 
Some authors have reported altered axioscapular muscle function in neck pain and increased upper trapezius activity alongside pain in patients with neck pain $[28,30$, 45]. Because we reported improved effects after TrPDN treatment of trigger points in the UT muscle and SCM, this increase could affect spinal and supraspinal mechanisms or both.

Myofascial Trigger Points Dry Needling (MTrPsDN) in UT muscle significantly reduces pain intensity in people with neck pain $[29,59,60]$. DN may mechanically stretch local sarcomeres. DN stimulates A-delta and activates enkephalin-producing neurons in the dorsal horn, reducing pain. It has been shown that DN may affect blood and muscle circulation and changes in the chemical properties of MTrPs [51]. So, because DN treatment reduces pain and improves function in patients with nonspecific neck pain, it improves tissue nutrition due to increased blood flow and reduces spasm [61].

Limitations of this study and suggestions for future studies

In this study, the effect of psychological factors, gender, and social factors was not examined. Because of the influence of psychological factors in reporting symptoms and the treatment process, future studies should consider psychological factors, and to solve the problems of each patient, a biological and psychological model (biosocial model) should be considered.

\section{Conclusion}

This study shows that adding dry needling to routine physiotherapy for patients with non-specific chronic neck pain can increase the effect of the intervention on the improvement of pain, disability, and changes in muscle thickness of SCM and UT.

\section{Ethical Considerations}

\section{Compliance with ethical guidelines}

This research was reviewed and approved by the Research Ethics Committee of the Faculty of Physical Education and Sport Science, University of Kharazmi, Tehran, Iran.

\section{Funding}

This research was supported by University of Kharazmi.

\section{Authors' contributions}

All authors equally contributed to preparing this article.

\section{Conflict of interest}

The authors declared no conflicts of interest.

\section{Acknowledgments}

We appreciate those who participated in the research for their valuable contributions. Also, we thank the Department of Biomechanics and Sports Injuries, Faculty of Physical Education and Sport Science, Kharazmi University for sponsoring the project.

\section{References}

[1] Fejer R, Kyvik KO, Hartvigsen J. The prevalence of neck pain in the world population: A systematic critical review of the literature. European Spine Journal. 2006; 15(6):834-48. [DOI:10.1007/s00586-004-0864-4] [PMID] [PMCID]

[2] Dimitriadis Z, Kapreli E, Strimpakos N, Oldham J. Hypocapnia in patients with chronic neck pain: Association with pain, muscle function, and psychologic states. American Journal of Physical Medicine \& Rehabilitation. 2013; 92(9):746-54. [DOI:10.1097/PHM.0b013e31829e74f7] [PMID]

[3] Jesus-Moraleida FRd, Pereira LSM, Vasconcelos CdM, Ferreira $\mathrm{PH}$. Multidimensional features of pain in patients with chronic neck pain. Fisioterapia em Movimento. 2017; 30(3):569-77. [DOI:10.1590/1980-5918.030.003.ao15]

[4] Ehsani F, Mosallanezhad Z, Vahedi G. The prevalence, risk factors and consequences of neck pain in office employees. Middle East Journal of Rehabiltation and Health Studies. 2017; 4(2):e42031. [DOI:10.5812/mejrh.42031]

[5] Touma J, May T, Isaacson AC. Cervical myofascial pain. StatPearls [Internet]. 2020. [Updated 2021 July 6] Available from: https://www.ncbi.nlm.nih.gov/books/NBK507825/

[6] Ribeiro DC, Belgrave A, Naden A, Fang H, Matthews P, Parshottam $S$. The prevalence of myofascial trigger points in neck and shoulder-related disorders: A systematic review of the literature. BMC Musculoskeletal Disorders. 2018; 19(252):1-13. [DOI:10.1186/s12891-018-2157-9] [PMID] [PMCID]

[7] Saleet Jafri M. Mechanisms of myofascial pain. International Scholarly Research Notices. 2014; 2014:523924. [DOI:10.1155/2014/523924] [PMID] [PMCID]

[8] Mejuto-Vázquez MJ, Salom-Moreno J, Ortega-Santiago R, Truyols-Domínguez S, Fernández-de-las-Peñas C. Shortterm changes in neck pain, widespread pressure pain sensitivity, and cervical range of motion after the application of trigger point dry needling in patients with acute mechanical neck pain: A randomized clinical trial. Journal of Orthopaedic \& Sports Physical Therapy. 2014; 44(4):252-60. [DOI:10.2519/jospt.2014.5108] [PMID] 
[9] Shah JP, Thaker N, Heimur J, Aredo JV, Sikdar S, Gerber L. Myofascial trigger points then and now: A historical and scientific perspective. PM \& R: The Journal of Injury, Function, and Rehabilitation. 2015; 7(7):746-61. [DOI:10.1016/j.pmrj.2015.01.024] [PMID] [PMCID]

[10] Fernández-de-Las-Peñas C, You Ge H, Alonso-Blanco C, Gonzalez-Iglesias J, Arendt-Nielsen L. Referred pain areas of active myofascial trigger points in head, neck, and shoulder muscles, in chronic tension type headache. Journal of Bodywork and Movement Therapies. 2010; 14(4):391-6. [DOI:10.1016/j. jbmt.2009.06.008] [PMID]

[11] Desai MJ, Saini V, Saini S. Myofascial pain syndrome: A treatment review. Pain and Therapy. 2013; 2(1):21-36. [DOI:10.1007/ s40122-013-0006-y] [PMID] [PMCID]

[12] Campa-Moran I, Rey-Gudin E, Fernández-Carnero J, ParisAlemany A, Gil-Martinez A, Lerma Lara S, et al. Comparison of dry needling versus orthopedic manual therapy in patients with myofascial chronic neck pain: A single-Blind, randomized pilot study. Pain Research and Treatment. 2015; 2015:327307. [DOI:10.1155/2015/327307] [PMID] [PMCID]

[13] Dunning J, Butts R, Mourad F, Young I, Flannagan S, Perreault T. Dry needling: A literature review with implications for clinical practice guidelines. Physical Therapy Reviews. 2014; 19(4):25265. [DOI:10.1179/108331913X13844245102034] [PMID] [PMCID]

[14] Li-Wei Chou, Yueh-Ling Hsieh, Ta-Shen Kuan, and ChangZern Hong. Needling therapy for myofascial pain: recommended technique with multiple rapid needle insertion. Biomedicine (Taipei). 2014; 4(2):13. [DOI:10.7603/s40681-014-0013-2] [PMID] [PMCID]

[15] Cummings TM, White AR. Needling therapies in the management of myofascial trigger point pain: A systematic review. Archives of Physical Medicine and Rehabilitation. 2001; 82(7):98692. [DOI:10.1053/apmr.2001.24023] [PMID]

[16] Dommerholt J, Thorp JN, Chou LW, Hooks T. A critical overview of the current myofascial pain literature. Journal of Bodywork and Movement Therapies. 2020; 24(2):213-24. [DOI:10.1016/j.jbmt.2020.04.001] [PMID]

[17] Kalichman L, Vulfsons S. Dry needling in the management of musculoskeletal pain. The Journal of the American Board of Family Medicine September. 2010; 23(5):640-6. [DOI:10.3122/ jabfm.2010.05.090296] [PMID]

[18] Rha DW, Shin JC, Kim YK, Jung JH, Kim YU, Lee SC. Detecting local twitch responses of myofascial trigger points in the lowerback muscles using ultrasonography. Archives of Physical Medicine and Rehabilitation. 2011; 92(10):1576-80. [DOI:10.1016/j. apmr.2011.05.005] [PMID]

[19] Teyhen DS. Painful and tender muscles: Dry needling can reduce myofascial pain related to trigger points muscles. Journal of Orthopaedic \& Sports Physical Therapy. 2013; 43(9):635. [DOI:10.2519/jospt.2013.0505] [PMID]

[20] Randall Hood S. What Are the Risks and Adverse Effects from Dry Needling? [Internet] [May 22, 2018] Available from: https://www.mcgowanhood.com/2018/05/22/ what-are-therisks-and-adverse-effects-from-dry-needling/

[21] Gattie E, Cleland JA, Snodgrass S. The effectiveness of trigger point dry needling for musculoskeletal conditions by physical therapists: A systematic review and meta-analysis. Journal of Orthopaedic \& Sports Physical Therapy. 2017; 47(3):133-49. [DOI:10.2519/jospt.2017.7096] [PMID]
[22] Bazin S, Kitchen S. Clayton's electrotherapy. London: Saunders; 1998. https:// www.worldcat.org/title/claytons-electrotherapy/oclc/992379780\&referer=brief_results

[23] Nalty T, Sabbahi MA. Electrotherapy clinical procedures manual. New York: McGraw-Hill; 2001. https://www. google.com/books/edition/Electrotherapy_Clinical_Procedures_Manua/aPZsAAAAMAAJ?hl=en

[24] Kisner C, Colby LA, John Borstad J. Therapeutic exercise: Foundations and techniques. Philadelphia: F. A. Davis Company; 2017. https://books.google.com/ books?id=yZc6DwAAQBAJ\&vq

[25] Travell JG, Simons DG. Myofascial pain and dysfunction: The trigger point manual. Baltimore: Williams \& Wilkins; 1983. https://www.worldcat.org/title/myofascial-pain-and-pyslunction-the-trigger-point-manual/ oclc/992211394\&referer=brief_results

[26] Dommerholt J, Fernández-de-las-Peñas C. Trigger point dry needling. E-Book: An Evidence and Clinical-Based Approach; 2018. https://www.elsevier.com/books/triggerpoint-dry-needling/dommerholt/978-0-7020-7416-5

[27] Martín-Rodríguez A, Sáez-Olmo E, Pecos-Martín D, CalvoLobo C. Effects of dry needling in the sternocleidomastoid muscle on cervical motor control in patients with neck pain: A randomised clinical trial. Acupuncture in Medicine. 2019; 37(3):151-63. [DOI:10.1177/0964528419843913] [PMID]

[28] Rezaeian T, Mosallanezhad Z, Nourbakhsh MR, Norouzi M, Sajedi F. Effects of dry needling technique into trigger points of the sternocleidomastoid muscle in migraine headache: A randomized controlled trial. American Journal of Physical Medicine \& Rehabilitation. 2020; 99(12):1129-37. [DOI: 10.1097/PHM.0000000000001504]

[29] Gerber LH, Shah J, Rosenberger W, Armstrong K, Turo D, Otto $\mathrm{P}$, et al. Dry needling alters trigger points in the upper trapezius muscle and reduces pain in subjects with chronic myofascial pain. PM \& R: The Journal of Injury, Function, and Rehabilitation. 2015; 7(7):711-8. [DOI:10.1016/j. pmrj.2015.01.020] [PMID] [PMCID]

[30] Ziaeifar M, Arab AM, Karimi N, Nourbakhsh MR. The effect of dry needling on pain, pressure pain threshold and disability in patients with a myofascial trigger point in the upper trapezius muscle. Journal of Bodywork and Movement Therapies. 2014; 18(2):298-305. [DOI:10.1016/j. jbmt.2013.11.004] [PMID]

[31] Price DD, Staud R, Robinson ME. How should we use the Visual Analogue Scale (VAS) in rehabilitation outcomes? II: Visual analogue scales as ratio scales: An alternative to the view of Kersten et al. Journal of Rehabilitation Medicine: Official Journal of the UEMS European Board of Physical and Rehabilitation Medicine. 2012; 44(9):800-1. [DOI:10.2340/16501977-1031] [PMID] [PMCID]

[32] MacDermid JC, Walton DM, Avery S, Blanchard A, Etruw E, Mcalpine C, et al. Measurement properties of the neck disability index: A systematic review. Journal of Orthopaedic \& Sports Physical Therapy. 2009; 39(5):400-17 [DOI:10.2519/ jospt.2009.2930] [PMID]

[33] Mousavi SJ, Parnianpour M, Montazeri A, Mehdian H, Karimi A, Abedi M, et al. Translation and validation study of the Iranian versions of the neck disability index and the Neck Pain And Disability Scale. Spine. 2007; 32(26):E825-31 [DOI:10.1097/BRS.0b013e31815ce6dd] [PMID] 
[34] O'Sullivan C, Persson UM, Blake C, Stokes M. Rehabilitative ultrasound measurement of trapezius muscle contractile states in people with mild shoulder pain. Manual Therapy. 2012; 17(2):139-44. [DOI:10.1016/j.math.2011.11.003] [PMID]

[35] Sikdar S, Shah JP, Gebreab T, Yen RH, Gilliams E, Danoff J, et al. Novel applications of ultrasound technology to visualize and characterize myofascial trigger points and surrounding soft tissue. Archives of Physical Medicine and Rehabilitation. 2009; 90(11):1829-38. [DOI:10.1016/j.apmr.2009.04.015] [PMID] [PMCID]

[36] O'Sullivan C, Meaney J, Boyle G, Gormley J, Stokes M. The validity of rehabilitative ultrasound imaging for measurement of trapezius muscle thickness. Manual Therapy. 2009; 14(5):572-8. [DOI:10.1016/j.math.2008.12.005] [PMID]

[37] Bokaee F, Rezasoltani A, Manshadi FD, Naimi SS, Baghban AA, Azimi H. Comparison of cervical muscle thickness between asymptomatic women with and without forward head posture. Brazilian Journal of Physical Therapy. 2017; 21(3):206-11. [DOI:10.1016/j.bjpt.2017.04.003] [PMID] [PMCID]

[38] Koo TK, Li MY. A guideline of selecting and reporting intraclass correlation coefficients for reliability research. Journal of Chiropratic Medicine. 2016; 15(2):155-63. [DOI:10.1016/j. jcm.2016.02.012] [PMID] [PMCID]

[39] Ilbuldu E, Cakmak A, Disci R, Aydin R. Comparison of laser, dry needling, and placebo laser treatments in myofascial pain syndrome. Photomedicine and Laser Therapy. 2004; 22(4):306-11. [DOI:10.1089/pho.2004.22.306] [PMID]

[40] Baldry P, Thompson JW. Acupuncture, trigger points and musculoskeletal pain: A scientific approach to acupuncture for use by doctors and physiotherapists in the diagnosis and management of myofascial trigger point pain. New York: Churchill Livingstone; 1993. https://www.ncbi.nlm.nih. gov/nlmcatalog/9206295

[41] Cerezo-Téllez E, Torres Lacomba M, Fuentes-Gallardo I Mayoral del Moral O, Rodrigo-Medina B, Gutiérrez Ortega C. Dry needling of the trapezius muscle in office workers with neck pain: A randomized clinical trial. Journal of Manual Manipulative Therapy. 2016; 24(4):223-32. [DOI:10.1179/ 2042618615Y.0000000004] [PMID] [PMCID]

[42] Liptan GL. Fascia: A missing link in our understanding of the pathology of fibromyalgia. Journal of Bodywork and Movement Therapies. 2010; 14(1):3-12. [DOI:10.1016/j. jbmt.2009.08.003] [PMID]

[43] Sterling M, Vicenzino B, Souvlis T, Connelly LB. Dryneedling and exercise for chronic whiplash-associated disorders: A randomized single-blind placebo-controlled trial. Pain. 2015; 156(4):635-43. [DOI:10.1097/01.j.pa in.0000460359.40116.c1] [PMID]

[44] Cagnie B, Barbe T, De Ridder E, Van Oosterwijck J, Cools A, Danneels L. The influence of dry needling of the trapezius muscle on muscle blood flow and oxygenation. Journal of Manipulative and Physiological Therapeutics. 2012; 35(9):685-91. [DOI:10.1016/j.jmpt.2012.10.005] [PMID]

[45] Téllez-García M, De-la-Llave-Rincón AI, Salom-Moreno J, Palacios-Ceña M, Ortega-Santiago R, Fernández-de-lasPeñas C. Neuroscience education in addition to trigger point dry needling for the management of patients with mechanical chronic low back pain: A preliminary clinical trial. Journal of Bodywork and Movement Therapies. 2015; 19(3):464-72. [DOI:10.1016/j.jbmt.2014.11.012] [PMID]
[46] Pecos-Martín D, Montañez-Aguilera FJ, Gallego-Izquierdo T, Urraca-Gesto A, Gómez-Conesa A, Romero-Franco N, et al. Effectiveness of dry needling on the lower trapezius in patients with mechanical neck pain: A randomized controlled trial. Archives of Physical Medicine and Rehabilitation. 2015; 96(5):775-81. [DOI:10.1016/j.apmr.2014.12.016] [PMID]

[47] Pavkovich R. The use of dry needling for a subject with acute onset of neck pain: a case report. International Journal of Sports Physical Therapy. 2015; 10(1):104-13. https:// www.ncbi.nlm.nih.gov/pmc/articles/PMC4325294/ [PMID] [PMCID]

[48] Rock JM, Rainey CE. Treatment of nonspecific thoracic spine pain with trigger point dry needling and intramuscular electrical stimulation: A case series. International Journal of Sports Physical Therapy. 2014; 9(5):699-711. https:/ / www.ncbi.nlm.nih.gov/pmc/articles/PMC4196334/ [PMID] [PMCID]

[49] León-Hernández JV, Martín-Pintado-Zugasti A, Frutos LG, Alguacil-Diego IM, De la Llave-Rincón AI, Fernandez-Carnero J. Immediate and short-term effects of the combination of dry needling and percutaneous TENS on post-needling soreness in patients with chronic myofascial neck pain. Brazilian Journal of Physical Therapy. 2016; 20(5):422-31. [DOI:10.1590/bjpt-rbf.2014.0176] [PMID] [PMCID]

[50] Rahou-El-Bachiri Y, Navarro-Santana MJ, Gómez-Chiguano GF, Cleland JA, López-de-Uralde-Villanueva I, Fernández-de-las-Peñas $C$, et al. Effects of trigger point dry needling for the management of knee pain syndromes: A systematic review and meta-analysis. Journal of Clinical Medicine. 2020; 9(7):2044. [DOI:10.3390/jcm9072044] [PMID] [PMCID]

[51] Dommerholt J. Dry needling - peripheral and central considerations. Journal of Manual \& Manipulative Therapy. 2011 Nov; 19(4):223-7. [DOI:10.1179/10669811 1X13129729552065] [PMID] [PMCID]

[52] Affaitati G, Costantini R, Fabrizio A, Lapenna D, Tafuri E, Giamberardino MA. Effects of treatment of peripheral pain generators in fibromyalgia patients. European Journal of Pain. 2011; 15(1):61-9. [DOI:10.1016/j.ejpain.2010.09.002] [PMID]

[53] Fernandez-Carnero J, La Touche R, Ortega-Santiago R, Galan-del-Rio F, Pesquera J, Ge HY, et al. Short-term effects of dry needling of active myofascial trigger points in the masseter muscle in patients with temporomandibular disorders. Journal of Oral \& Facial Pain and Headache. 2010; 24(1):106-12. http://www.quintpub.com/journals/ofph/ full_txt_pdf_alert.php?article_id=7753 [PMID]

[54] Hsieh YL, Kao MJ, Kuan TS, Chen SM, Chen JT, Hong CZ. Dry needling to a key myofascial trigger point may reduce the irritability of satellite MTrPs. American Journal of Physical Medicine \& Rehabilitation. 2007; 86(5):397-403. [DOI:10.1097/PHM.0b013e31804a554d] [PMID]

[55] Lewit K. The needle effect in the relief of myofascial pain. Pain. 1979; 6(1):83-90. [DOI:10.1016/0304-3959(79)90142-8]

[56] Lucas KR, Polus BI, Rich PA. Latent myofascial trigger points: their effects on muscle activation and movement efficiency. Journal of Bodywork Movement Therapies. 2004; 8(3):160-6 [DOI:10.1016/j.jbmt.2003.12.002] 
[57] Lucas KR, Rich PA, Polus BI. Muscle activation patterns in the scapular positioning muscles during loaded scapular plane elevation: The effects of latent myofascial trigger points. Clinical Biomechanics. 2010; 25(8):765-70 [DOI:10.1016/j.clinbiomech.2010.05.006] [PMID]

[58] Shah JP, Phillips T, Danoff JV, Gerber LH. A novel microanalytical technique for assaying soft tissue demonstrates significant quantitative biomechanical differences in 3 clinically distinct groups: Normal, latent and active. Archives of Physical Medicine and Rehabilitation. 2003; 84(9):A4. https://www. archives-pmr.org/article/S0003-9993(03)00525-2/abstract

[59] Shah JP, Danoff JV, Desai MJ, Parikh S, Nakamura LY, Phillips TM, et al. Biochemicals associated with pain and inflammation are elevated in sites near to and remote from active myofascial trigger points. Archives of Physical Medicine and Rehabilitation. 2008; 89(1):16-23. [DOI:10.1016/j. apmr.2007.10.018] [PMID]

[60] Manafnezhad J, Salahzadeh Z, Salami M, Ghader F, Ghojazadeh $\mathrm{M}$. The effects of shock wave and dry needling on active trigger points of upper trapezius muscle in patients with non-specific neck pain: A randomized clinical trial. Journal of Back and Musculoskeletal Rehabilitation. 2019; 32(5):811-8. [DOI:10.3233/BMR-181289] [PMID]

[61] Häkkinen A, Salo P, Tarvainen U, Wiren K, Ylinen J. Effect of manual therapy and stretching on neck muscle strength and mobility in chronic neck pain. Journal of Rehabilitation Medicine. 2007; 39(7):575-9. [DOI:10.2340/16501977-0094] [PMID] 